\title{
Treatment of vaginal candidosis with a single 500-mg clotrimazole pessary
}

\author{
IAN MILSOM AND LARS FORSSMAN \\ From the Department of Obstetrics and Gynaecology, East Hospital, Gothenburg, Sweden
}

SUMMARY In a double-blind study the therapeutic efficacy of a single 500-mg clotrimazol pessary was compared with that of a $200-\mathrm{mg}$ clotrimazole pessary inserted once daily for three. days in 72 patients with vaginal candidosis confirmed by culture. On clinical assessment fougi weeks after completion of treatment with the single-dose pessary the cure rate was $86 \%$ compared with $92 \%$ after the three-day regimen. There was no significant difference in the eradication rat $E_{0}$ between the single-dose $(94 \%)$ and three-day regimens $(89 \%)$. Four weeks after completion of treatment the recurrence rates by culture were $18 \%$ with the single-dose and $24 \%$ with the three day regimen. The former treatment was well tolerated and as effective as the three-das clotrimazole regimen.

\section{Introduction}

Clotrimazole, one of the imidazole antimycotics, in a dosage of $100 \mathrm{mg}$ given for six days was found to be effective in the treatment of vaginal candidosis. ${ }^{1}$ Shorter periods of treatment of four ${ }^{2}$ or three ${ }^{34}$ days did not affect the efficacy of the treatment. Clotrimazole is fungicidal in vaginal secretions at a concentration of $>10 \mu \mathrm{g} / \mathrm{ml}^{5}$ and remains at this concentration for 72 hours after insertion of one $500-\mathrm{mg}$ clotrimazole pessary (Ritter et al, unpublished data). We evaluated, therefore, the therapeutic efficacy and local tolerance of a single $500-\mathrm{mg}$ clotrimazole pessary for the treatment of vaginal candidosis.

\section{Patients and methods}

Women with all the following criteria for vaginal candidosis were included in the study: (a) symptoms of irritation, burning, and vaginal discharge; (b) signs of inflammation of the vaginal mucosa and microscopical identification of pseudohyphae; and (c) cultural isolation of Candida albicans.

The culture specimens were promptly inoculated on to standard media and growing yeasts were identified as $C$ albicans by the formation of

Address for reprints: Dr I Milsom, Department of Obstetrics and Gynaecology, East Hospital, S-416 85 Göteborg, Sweden

Accepted for publication 23 November 1981 chlamydospores and the germ tube test. Pregnant patients and those who had received antifungal of antitrichomonal treatment during the previous twe weeks were excluded. Treatment with hormones o. antibiotics, the use of an intrauterine contraceptive device, any previous treatment for vagina candidosis, and the presence or absence of vulviti $\overrightarrow{5}$ (defined as irritation, swelling, and redness of the vulva) were recorded.

Cultures for Neisseria gonorrhoeae and Chlamydia. trachomatis and microscopical examination to exclude Trichomonas vaginalis were performe before the patient started treatment.

\section{TREATMENT}

Patients were supplied with a plain numbered pack containing three pessaries marked day 1 to day 3 Each pack contained either one clotrimazol $(500 \mathrm{mg})$ pessary plus two placebo pessaries or thres clotrimazole $(200 \mathrm{mg})$ pessaries. The active an\$ placebo pessaries were indistinguishable. The cors tainers were prepacked and randomised so that neither the clinician, the mycologist, nor the patient knew which treatment was being given. The firs pessary was inserted at the completion of the gynaecological examination by one of us. The resmaining pessaries were inserted once daily by theo patient from the following night. Patients wit vulvitis were also given clotrimazole cream an $\$$ instructed to apply it to the vulva. No attempt waळ made to treat the sexual partner. 
FOLLOW UP

Patients were examined one and four weeks after the completion of treatment. At each follow up, the clinical symptoms were recorded using a three-point severity scale $(0=$ none, $1=$ moderate, $2=$ severe $)$. A high vaginal swab was taken and examined with a light microscope for pseudohyphae and by culture for Candida species.

STATISTICAL ANALYSIS

The results of the two treatment regimens were compared using the $\chi^{2}$ test with Yates's correction (significance, $\mathrm{P}<0.05$ ).

\section{Results}

As treatment was started before mycological confirmation it was necessary to exclude seven women with negative culture results for Candida and one with positive culture results for both $C$ albicans and $C$ trachomatis. None of the patients had gonorrhoea as judged by culture samples from the cervix, urethra, and rectum. Seventy-two patients, ranging in age from 16-56 years, satisfied the criteria for inclusion and subsequently completed the trial. The characteristics of the two groups were similar (table I). The severity of clinical symptoms and signs are shown in table II.

TABLE I Comparison of patients treated with either a single 500-mg clotrimazole pessary (group I) or a 200-mg clotrimazole pessary for three days (group 2)

\begin{tabular}{lll}
\hline & $\begin{array}{l}\text { Group I } \\
(n=35)\end{array}$ & $\begin{array}{l}\text { Group 2 } \\
(n=37)\end{array}$ \\
\hline $\begin{array}{l}\text { Age (years, mean } \pm \mathrm{SD} \text { ) } \\
\text { Previously treated for } \\
\quad \text { vaginal candidosis }\end{array}$ & $27 \cdot 4 \pm 7 \cdot 6$ & $29 \cdot 0 \pm 6.9$ \\
$\begin{array}{l}\text { Vulvitis } \\
\text { Antibiotic treatment in } \\
\quad \text { month before trial }\end{array}$ & 18 & 19 \\
$\begin{array}{l}\text { Contraceptive pill } \\
\text { Other hormone treatment }\end{array} \quad 33$ & 35 \\
$\quad$ (for example, oestrogen) & 1 & 0 \\
Intrauterine contraceptive device & 15 & 15 \\
\hline
\end{tabular}

$\mathrm{n}=$ No of patients treated; $\mathrm{SD}=$ standard deviation

\section{CURE RATES}

One week after completing treatment one patient in each of the two groups had signs and symptoms of vaginal candidosis (table III). They were retreated with 100-mg clotrimazole pessaries for six days. Four weeks later both patients were free of symptoms and culture results for $C$ albicans were negative.

TABLE III Patients with positive culture results for $C$ albicans or signs and symptoms of infection one week and four weeks after completion of treatment

Results after completion of treatment (weeks):

\begin{tabular}{|c|c|c|c|c|}
\hline & \multicolumn{2}{|c|}{$\begin{array}{l}\text { Group } I^{*} \\
(n=35)\end{array}$} & \multicolumn{2}{|c|}{$\begin{array}{l}\text { Group 2* } \\
(n=37)\end{array}$} \\
\hline & $I$ & 4 & $I$ & 4 \\
\hline $\begin{array}{l}\text { Positive culture result } \\
\text { Clinical signs and symptoms }\end{array}$ & $\begin{array}{l}2 \\
1\end{array}$ & $\begin{array}{l}6 \\
5\end{array}$ & $\begin{array}{l}4 \\
1\end{array}$ & $\begin{array}{l}8 \\
3\end{array}$ \\
\hline
\end{tabular}

* Group 1: treated with a single 500-mg clotrimazole pessary; group

2: treated with a $200-\mathrm{mg}$ clotrimazole pessary for three days.

Four weeks after completing treatment five patients who had received a single $500-\mathrm{mg}$ clotrimazole pessary and three the three-day regimen had signs and symptoms of vaginal candidosis (table III). This gave a cure rate of $85 \cdot 7 \%$ four weeks after completion of the single-dose regimen and $91.9 \%$ for the patients given the three-day regimen. The difference in cure rates was not statistically significant $\left(\chi_{1}^{2}=0 \cdot 21, \mathrm{P}>0 \cdot 05\right)$.

\section{ERADICATION RATE}

The eradication rate, based on a negative culture result for $C$ albicans, seven days after treatment with a single clotrimazole pessary was $\mathbf{9 4 . 3 \%}$ and that for the three-day regimen $89 \cdot 2 \%$ (table III). The difference in eradication rates was not statistically significant $\left(\chi_{1}^{2}=0 \cdot 13, \mathrm{P}>0.05\right)$.

RECURRENCE RATE

Four weeks after completion of treatment the recurrence rate, as judged by culture, was $18 \cdot 2 \%$ with

TABLE II Total symptom score in the two treatment groups before and one and four weeks after completion of treatment

\begin{tabular}{|c|c|c|c|c|c|c|}
\hline \multirow[b]{3}{*}{ Symptoms } & \multicolumn{6}{|c|}{ Severity of symptoms* } \\
\hline & \multicolumn{3}{|c|}{$\underset{(n=35)}{\text { Group I† }}$} & \multicolumn{3}{|c|}{$\underset{(n=37)}{\operatorname{Group}} 2+$} \\
\hline & Pretrial & $I$ week after & 4 weeks after & Pretrial & $I$ week after & 4 weeks after \\
\hline $\begin{array}{l}\text { Itching } \\
\text { Burning } \\
\text { Discharge }\end{array}$ & $\begin{array}{l}69 \\
63 \\
59\end{array}$ & $\begin{array}{l}2 \\
0 \\
1\end{array}$ & $\begin{array}{l}7 \\
1 \\
1\end{array}$ & $\begin{array}{l}73 \\
68 \\
61\end{array}$ & $\begin{array}{l}5 \\
1 \\
3\end{array}$ & $\begin{array}{l}7 \\
5 \\
4\end{array}$ \\
\hline
\end{tabular}

* Severity scale: $0=$ none, $1=$ moderate, $2=$ severe

+ Group 1: treated with a single $500-\mathrm{mg}$ clotrimazole pessary; group 2: treated with a $200-\mathrm{mg}$ clotrimazole pessary for three days $\mathrm{n}=$ No of patients treated 
the single-dose regimen and $24 \cdot 2 \%$ with the threeday regimen (table III). The difference in recurrence rates was not statistically significant $\chi_{1}^{2}=0.09$, $p>0.05)$. None of the patients treated reported any side effects.

\section{Discussion}

Treatment of vaginal candidosis with a single $500-\mathrm{mg}$ clotrimazole pessary was found to be as effective as previous treatment regimens of longer duration. ${ }^{237}$ In the present investigation over $50 \%$ of the patients had been treated previously for vaginal candidosis, many several times each year. The duration and nature of the treatment is of special importance to women who have experienced repeated episodes of vaginal candidosis. Treatment with a single $500-\mathrm{mg}$ clotrimazole pessary is an effective, simple, and acceptable regimen. The pessary can be inserted during the patient's clinic attendance as soon as the diagnosis is confirmed, which removes the problem of patient compliance and offers maintained efficacy? and maximum acceptability.

\section{References}

1. Masterton G, Henderson J, Napier IR Moffet M. Six-day clotrimazole therapy in vaginal candidiasis. Curr Med ReS Opin 1975; 3: 83-8.

2. Milsom I, Forssman L. A double-blind trial of 4-days and 6-days therapy with clotrimazole in vaginal candidiasis $\vec{\circ}$ Pharmatherapeutica 1978; 2:8-11.

3. Masterton G, Napier IR, Henderson JN, Roberts JE. Three $\overrightarrow{-}$ day clotrimazole treatment in candidal vulvovaginitis. $\mathrm{Br}$ Vener Dis 1977; 53:126-8.

4. Widholm O, Vartiainen E. Short-term clotrimazole treatmen? of vaginal candidosis. Curr Ther Res 1980;28:511-4.

5. Iwata $K$, Yamaguchi $H$, Hiratani T. Mode of action oD clotrimazole. Sabouraudia 1973;11:158-66.

7. Highton BK. A trial of clotrimazole and nystatin in vaginaL moniliasis. Journal of Obstetrics and Gynaecology of the British Commonwealth 1973;80:992-5. 